\title{
Dependência química e fortalecimento psicossocial pelas práticas esportivas
}

Marcelo Simões Mendes. Universidade Paulista de Campinas

\section{Resumo}

A questão sobre o abuso de drogas tem manifestado a urgência por medidas que fomentem o tratamento sobre a mesma. $O$ presente relato de experiência profissional procurou apresentar uma proposta de intervenção em que a prática esportiva foi utilizada como importante instrumento no processo de tratamento para pessoas com dependência de álcool e outras drogas. Foi percebido que a prática esportiva colaborou para o desenvolvimento dos recursos internos dos participantes, atuando como medida para o fortalecimento psicossocial dos usuários por meio do desenvolvimento da autoestima, perseverança, disciplina, superação, dentre outros.

Palavras-chave: intervenção psicossocial; reabilitação da droga; esportes.

\begin{abstract}
Chemical dependency and strengthening psychosocial by sports practices. The question of drug use has shown the urgent need for measures to promote the treatment of this question. This account of professional experience presented a proposal for intervention in which sports practice was used as an important tool in the treatment process for people with alcohol and others drugs. It was noticed that the sports practice contributed to the development of the internal resources of the participants, acting as a measure for the psychosocial strengthening of users through the development of self-esteem, perseverance, discipline, overcoming, among others.
\end{abstract}

Keywords: psychosocial intervention; drug rehabilitation; sports.

\section{Resumen}

Dependencia química y fortalecimiento psicosocial por prácticas deportivas. La cuestión del uso de drogas ha demostrado la necesidad urgente de medidas para promover el tratamiento de la misma. Este relato de la experiencia profesional trató de presentar una propuesta de intervención en que se utilizó la práctica del deporte como una herramienta importante en el proceso de tratamiento para las personas con dependencia del alcohol y otras drogas. Se observó que la práctica deportiva ha contribuido al desarrollo de los recursos internos de los participantes, que actúa como una medida para el fortalecimiento psicosocial de los usuarios a través del desarrollo de la autoestima, la perseverancia, la disciplina, la superación, entre otros. Palabras clave: intervención psicosocial; rehabilitación de la drogadicción; deportes. 
Segundo o relatório mundial sobre o uso de drogas apresentado pela United Nations Office on Drugs and Crime (UNODC) (2015), há uma estimativa que 5\% da população mundial com idade entre 15 e 64 anos utilizou drogas ilícitas em 2013, o que equivale há um total de 246 milhões de pessoas. Deste total, cerca de 27 milhões apresentaram um grau mais intenso de dependência química.

A questão da dependência química tem sido alvo de discussão em diversas áreas no campo da Saúde no Brasil, mobilizando ações que não se reduzem a uma única área de conhecimento ou especialidade, mas próprias de uma proposta de intersetorialidade tendo em vista a complexidade que envolve os problemas dessa natureza. Devido à multiplicidade de olhares que convergem para esta discussão, diversas têm sido as contribuições segundo a especialidade que trata dessa temática, envolvendo ações que compreendem medidas de avaliação (Kaup, Merighi, \& Tsunechiro, 2001; Soares \& Jacobi, 2000) - a partir de modelos ampliados (Galduróz, 2001) inseridos, por exemplo, na concepção biopsicossocial -, propostas de natureza profilática (Monteiro, Vargas, \& Rebello, 2003) - identificando os fatores de vulnerabilidade que potencializam o acesso e o consumo de drogas -, assim como as medidas que se dirigem à implementação de programas de tratamento e reabilitação para usuários de substâncias psicoativas.

Em relação ao uso de álcool no Brasil, o estudo de Galduróz e Caetano (2004) apresenta um levantamento populacional específico desse consumo em vários contextos. No ensino fundamental e médio, quatro estudos investigaram o uso de álcool entre os estudantes em 10 capitais brasileiras nos anos de 1987, 1989, 1993 e 1997. Dentre os alunos que faziam uso pesado (20 vezes ou mais por mês), em todas as capitais este percentual aumentou ao longo dos anos. Já o estudo de Passos (2011) analisou as internações decorrentes do uso de substâncias psicoativas no Distrito Federal entre os anos de 2000 e 2009. Os resultados revelaram que o uso de álcool, múltiplas drogas e cocaína entre adultos jovens do sexo masculino foram as principais causas de internação.

Especialmente em relação ao uso do crack, no Brasil estas medidas têm tido um crescente reconhecimento devido, principalmente, às especificidades conferidas a esta droga e pelo aumento significativo de usuários em diversas regiões do país. Ainda que o consumo de crack possa ser considerado um fenômeno recente
(Ribeiro \& Laranjeira, 2010), este tem despertado uma preocupação cada vez maior de profissionais da saúde e pesquisadores a partir do início deste século (Kessler \& Pechansky, 2008).

Segundo Duailibi, Ribeiro e Laranjeira (2008), o consumo de crack tem apresentado uma relação direta com a infecção pelo HIV. Para estes autores, isto se dá pelo grande número de parceiros dos usuários, pela desproteção em relações sexuais e mesmo pela troca do sexo por crack. No caso da violência, Ribeiro e Laranjeira (2010) afirmam que este fator parece ter uma estreita relação com o consumo de crack, especialmente quando relatam que a violência tem aumentado em consonância com a elevação do consumo desta droga no Brasil.

De fato, ficam evidentes os impactos e consequências para a saúde das pessoas que fazem uso do álcool e outras drogas. No entanto, algumas medidas, sejam essas de caráter profilático ou voltadas para a reabilitação, tendem a colaborar para que mudanças ocorram neste cenário.

Em relação a uma destas medidas, destaca-se o uso das práticas esportivas como instrumento no processo de reabilitação para pessoas que possuem algum grau de dependência química. A atividade física e o esporte têm demonstrado benefícios que se estendem para além da otimização das capacidades funcionais do organismo humano. Além da atividade física e do esporte contribuírem para uma menor incidência de doenças crônico-degenerativas (Carvalho et al., 1996), estes, por sua vez, podem atuar também colaborando para a promoção da formação integral sujeito.

Sobre esta última incidência, Di Pierro e Silva (2003) apontam o esporte como um meio de educação para a vida, que pode contribuir para o desenvolvimento integral e crítico do cidadão. No entanto, os autores alertam que para este fim, o esporte deve ser entendido para "[...] além da formação atlética-técnico-tática e priorizar valores como cooperação, a participação, a solidariedade e a criatividade das crianças e jovens [...]" (pp. 147), além de considerar estes jovens como participantes ativos desse processo pelo qual estão envolvidos.

Nesta perspectiva é possível encontrar estudos que têm discutido a questão do esporte enquanto ferramenta auxiliadora na formação educacional do sujeito. Llamas e Suárez (2004) apontam alguns dos valores pessoais e sociais possíveis de serem desenvolvidos por 
meio do esporte, a saber: desejo de superação, integração, respeito ao próximo, tolerância, respeito às regras, perseverança, trabalho em equipe, superação de limites, disciplina pessoal, responsabilidade, cooperação, honestidade, lealdade, entre outros. Estes valores podem ser associados, direta ou indiretamente, ao fortalecimento e manutenção da autoestima do sujeito, além corroborar para a realização pessoal e formação integral do mesmo.

No aprofundamento dessa discussão, torna-se necessário ter cautela ao se estabelecer uma relação entre esporte e educação já que assim como indicam Freire, Cárdenas, Manzano, e Enriquéz (2014), tal relação é polissêmica e pode ser desenvolvida de diferentes formas a partir das concepções ideológicas que envolvem os termos educação e esporte. Nessa mesma linha de pensamento, Romera (2013) alerta para a necessidade de não se estabelecer uma relação simplista de que a prática esportiva por si só garante a imunidade para o uso e abuso de drogas.

Nessa perspectiva mais crítica e ampliada sobre as relações entre prática esportiva, educação e uso de substâncias psicoativas, poucos estudos têm tratado sobre tal temática, especialmente quando se referem as discussões construídas a partir de um diálogo com a experiência aplicada no contexto da atenção psicossocial e promoção da saúde mental. Diante dessa exposição, o presente estudo se propôs a relatar a experiência desenvolvida a partir de um trabalho que utilizou a prática esportiva como instrumento no processo de reabilitação junto a usuários que buscavam tratamento para a dependência química em um centro de atenção psicossocial álcool e outras drogas (CAPSAD). Para tanto, após a exposição do método serão apresentados na sessão de resultados e discussão uma breve caracterização do trabalho, dos usuários e dos profissionais, juntamente com algumas reflexões sobre como a prática esportiva foi percebida no desenvolvimento do referido trabalho com os usuários.

\section{Método}

\section{Caracterização da Prática}

O trabalho foi desenvolvido junto aos usuários que buscavam tratamento em uma unidade do CAPS $A D^{1}$ de uma cidade de grande porte do interior paulista. As atividades aconteciam uma vez por semana e duravam entre uma e duas horas por encontro. A modalidade esportiva que foi utilizada nos encontros foi o futebol por escolha dos usuários e estes encontros foram desenvolvidos em um campo próximo à instituição. As atividades com o futebol realizadas na instituição aconteciam desde 2007. Contudo, o presente estudo se incumbiu de descrever o relato da experiência vivenciada pelo autor durante o ano de 2012, período em que o mesmo participou das atividades em questão.

Os usuários eram provenientes de diferentes realidades sociais, desde moradores de rua até jovens de classe de média, com uma proporção maior de pessoas com renda inferior a dois salários mínimos e muitos deles apenas com trabalhos informais. Quanto à tipologia das drogas utilizadas, os usuários buscavam tratamento principalmente para a dependência de álcool, cocaína e crack. Todos os participantes eram do sexo masculino e devido à alta rotatividade de usuários na instituição é difícil apresentar um número exato sobre quantos participaram das atividades no referido período. Entretanto, é possível afirmar que havia pelo menos 15 usuários em cada encontro. Todos os participantes eram do sexo masculino.

O grupo de profissionais responsáveis pela condução das atividades era composto por: dois psicólogos, um enfermeiro, um profissional de Educação Física, dois estagiários de enfermagem e dois de psicologia.

\section{Registro dos Dados}

Durante o ano de 2012, os dados referentes às observações e a experiência vivenciada eram registrados semanalmente logo após o término da prática do futebol. Ao final desse período, o autor construiu um relatório segundo o qual continha registrado todas as observações assim como uma análise de toda a experiência desenvolvida nesse período à luz da literatura conveniente com os fenômenos observados. Parte desse material foi utilizado para a construção do presente estudo.

\section{Cuidados Éticos na Exposição dos Dados}

A partir das considerações da resolução 466/2012 que apresenta as diretrizes e normas regulamentadoras de pesquisas envolvendo seres humanos, o presente relato de experiência considerou ser necessário estar apoiado nessas diretrizes especialmente no que se refere à exposição dos dados. Especificamente, tal exposição foi cuidadosamente construída de maneira a assegurar a confidencialidade e a privacidade dos participantes envolvidos, garantindo a não utilização das informações em prejuízo dos mesmos. 


\section{Resultados e discussão}

\section{A Dependência Química e a Exclusão Social como Fator de Vulnerabilidade}

Não apenas nos encontros das atividades com o futebol, mas assim como em outras oportunidades de contato com usuários - rodas de conversa, conversas individuais -, estes, por sua vez, relataram o quanto a dependência química propiciou para que se sentissem excluídos de muitas esferas sociais. Muitos perderam o contato com suas famílias e outros perderam seus empregos. Este cenário foi percebido como um estado de significativa vulnerabilidade social.

Sob a ótica da exclusão social, compreende-se que este fenômeno é complexo e multifacetado e que, envolvem dimensões materiais, políticas, relacionais e subjetivas (Sawaia, 2013a). A autora conceitua a exclusão não como um estado, mas como um processo que não apresenta uma única forma, pois do ponto de vista da dialética, este expressa um processo perverso que vai além de uma falha do sistema, sendo portanto, produto do funcionamento do sistema.

Ainda se tratando da questão da exclusão social, Sawaia (2013b) trata este processo a partir do conceito de sofrimento ético-político. Baseada em alguns autores como Heller, Espinosa e Vigotsky, a autora discorre que o sofrimento se diferencia da dor uma vez que a dor é definida como algo próprio da vida humana, sendo assim inevitável. Já o sofrimento é considerado como a dor mediada pelas injustiças sociais (Sawaia, 2013b). Sob esta distinção, o sofrimento está atrelado aos afetos e significados enunciados pela organização social, sendo próprios e distintos segundo cada momento histórico. A título de exemplificação, a culpa e a vergonha são apresentados, em dado momento histórico, como sentimentos ligado à moral capazes de instituir e manter a ordem social excludente (Heller citado por Sawaia, 2013b).

Tal ordem excludente permeia o imaginário social contribuindo para que usuários de drogas se sintam culpados e envergonhados por suas dependências (Marques-Teixeira, 2001). A culpa e a vergonha também são sentimentos experenciados pelos familiares dos usuários de drogas (Siqueira et al., 2012), fazendo com que tais sentimentos tendam a fomentar para que os mesmos se sintam, cada vez mais, sem direito a participar de alguns contextos sociais. Contudo, a prática esportiva vem a contribuir em um sentido contrário às características de exclusão que este contexto pode provocar. A próxima sessão tratará de expor com mais detalhes os benefícios desta prática.

\section{Empowerment e Prática Esportiva: Mecanismo de Proteção Frente aos Fatores de Risco}

Como apontado anteriormente, o esporte teve um papel colaborativo não apenas em relação enfrentamento da exclusão social como também a outros fatores de risco. O vínculo com o grupo, o sentimento de cooperação, de ajuda mútua e de unidade grupal proporcionados pela prática esportiva foram percebidos como importantes mecanismos de proteção frente ao cenário de exclusão social percebidos neste contexto.

Como indicado por Llamas e Suárez (2004), estes e outros valores sociais proporcionados pelo desenvolvimento das práticas esportivas podem colaborar ao fortalecimento e manutenção da autoestima do sujeito, assim como por sua realização pessoal. Sendo assim, a prática esportiva, especialmente voltada ao contexto da drogadição, tende a repercutir para o fortalecimento psicossocial de seus praticantes, empoderando2estes usuários frente aos desafios e fatores de risco que, muitas vezes, são inerentes às suas condições. A título de exemplificação, com o desenvolvimento de recursos de internos para o enfrentamento de recaídas e reutilização de drogas.

Contudo, os benefícios desta transformação do sujeito podem se estender não apenas para a proteção do usuário frente aos fatores de risco específicos ao contexto da dependência química, mas na possibilidade de ampliar seu repertório de atuação nos ambientes sociais onde participa, especialmente por meio de um posicionamento crítico nestes ambientes.

Ainda que esta proposta de transformação do sujeito possa se apresentar como um ideal norteador para as práticas interventivas, é cabível apontar que as transformações em situações de vulnerabilidade são complexas e não podem ser entendidas apenas e exclusivamente sob a perspectiva do sujeito sem considerar sua interação com o meio social em uma relação dialética e sócio-histórica. Na perspectiva de Lane (2006), compreender o sujeito a partir dessa concepção significa superar a dicotomia indivíduo/grupo já que o contexto social é anterior a existência do sujeito e compreender o mesmo separada de seu contexto pode significar lançar mão de uma compreensão reducionista e por vezes, equivocada. Sendo assim, o sujeito não é apenas produto das determinações exteriores e interiores a si (Mailhiot, 2013), e necessita ser entendido, a partir de sua relação dialética com o contexto social, como produto e produtor tanto de sua história individual quanto coletiva (Lane, 2006). 
Nesta perspectiva, as intervenções direcionadas às populações em vulnerabilidade social, suscitam transformações deste contexto a partir da ação dos próprios integrantes com a comunidade pela qual estão inseridos. Por este motivo, intervenções desta natureza adquirem maior consistência quando apoiadas, entre outros, no conceito denominado empowerment.

Há uma discussão e preocupação na literatura a respeito do uso deste conceito em programas de promoção da saúde. Uma destas preocupações se deve ao fato da compreensão equivocada deste conceito principalmente devido à complexidade implícita na concepção de empowerment.

Segundo Carvalho (2004a), a complexidade para o entendimento do conceito empowerment está associada ao fato deste possuir raízes em vários campos de conhecimento. No exercício da tradução do empowerment para os idiomas português e espanhol, este tem se assumido como sinônimo de "empoderamento", "apoderamento" e "emancipación". O termo "empoderamento" não existe na língua portuguesa e já o termo "apoderamento" é sinônimo de dar posse, "apossar-se", "conquistar". Já as definições relacionadas ao verbo "emancipar" significam "tornar livre, independente" (Carvalho, 2004a).

Ainda que o termo empowerment possa assumir múltiplos sentidos, Carvalho (2004a) aponta a necessidade de compreensão deste conceito a partir de respostas frente a questões aplicadas a este, como: O que está por trás desta categoria? Qual teoria sobre poder este conceito se apoia? Processos de empowerment devem se direcionar para mudanças individuais ou coletivas? Qual a relação entre empowerment e a comunidade? A partir destas e outras questões, este autor reflete sobre duas concepções distintas sobre a categoria empowerment no ideário da Promoção à Saúde - a concepção psicológica e a comunitária.

Segundo Carvalho (2004a, 2004b), o empowerment psicológico pode ser definido como o sentimento de maior controle sobre a própria vida que sujeitos venham a apresentar por meio do pertencimento a diferentes grupos. Sob esta concepção deriva a formulação de estratégias que visam à promoção deste sujeito com o intuito de fortalecer sua autoestima, sua capacidade de adaptação ao meio e o desenvolvimento de mecanismos de autoajuda e solidariedade. A figura do indivíduo sob o enfoque psicológico do empowerment reflete uma pessoa comedida, independente, autoconfiante e que seja capaz de influenciar o seu meio e atuar de acordo com os princípios de justiça e equilíbrio (Rigger citado por Carvalho, 2004b).

O empowerment comunitário trabalha com a noção de poder como um recurso, material e não-material, distribuído de maneira desigual na sociedade. Desta maneira, esta estratégia defende uma postura ativa frente às determinações macro e microssociais de desigualdade social, atuando assim como um processo de redistribuição do poder nas esferas pessoais, intersubjetivas e políticas. O empowerment comunitário suscita a elaboração de estratégias que visem à promoção de indivíduos e coletivos para que possam definir, analisar e atuar sobre seus próprios problemas e sobre sua própria realidade (Carvalho, 2004a, 2004b).

Aliado ao contexto da exclusão social, outros fatores de risco foram percebidos durante o desenvolvimento das atividades. A depressão, a ansiedade, a angústia e o declínio da autoestima também estiveram presentes dentre o relato dos usuários durante conversas ao longo do período em contato com os mesmos. Sendo assim, o empowerment, seja ele psicológico ou comunitário, pode se apresentar como um importante instrumento pelo fato auxiliar o sujeito para lidar com estes fatores de risco de maneira mais construtiva e positiva uma vez que o considera como sujeito ativo em seu processo de promoção da saúde.

Ao final dessa experiência, foi percebido um crescente entusiasmo da maioria dos usuários pela prática esportiva. Esse entusiasmo também esteve associado às mudanças corporais proporcionadas pela prática do futebol. Alguns usuários disseram se sentir mais satisfeitos com sua imagem corporal devido à perda de peso proporcionado pela prática esportiva e outros relataram estarem mais dispostos e confiantes para a prática sexual/afetiva junto às suas parceiras.

Conforme indicado por alguns estudos (MarquesTeixeira, 2001), a dependência química pode gerar junto aos usuários sentimentos de culpa, vergonha e incapacidade frente à dependência. Tais sentimentos podem acarretar em profundos prejuízos para constituição afetiva do sujeito, fazendo com que muitas vezes esse indivíduo se sinta inseguro e fragilizado para poder participar de muitos espaços sociais e de construir novos relacionamentos.

Como identificado na experiência com o futebol, os usuários relataram o quanto se sentiram mais dispostos e confiantes para a busca de relacionamentos afetivos. Ao estender a compreensão sobre o alcance desse resultado, torna-se necessário destacar a importância 
desse aspecto dentro de um processo amplo e complexo que é o da reabilitação psicossocial. Frente aos fatores de risco que permeiam o contexto da drogadição (risco de reincidência, tristeza, culpa, vergonha, entre outros), o empoderamento de se sentir mais confiantes para a busca de novos relacionamentos e de outras fontes de prazer (tendo em vista que a prática esportiva libera endorfina - hormônio responsável pela sensação de prazer e bem-estar), pode funcionar como um importante fator de proteção. Concomitante a esse aspecto, o entusiasmo e a confiança podem atuar como um aspecto propulsor para maior engajamento no processo de reabilitação assim como contribuir para que os usuários se sintam mais fortalecidos para recusar a reincidência no uso de drogas, especialmente em momentos de vulnerabilidade.

Partindo do pressuposto de que a atenção psicossocial e a promoção da saúde mental do sujeito que perpassa pela experiência da dependência química é um processo dinâmico e multifacetado, carregada por muitas nuances e particularidades, é necessário considerar que as ações desenvolvidas em qualquer instância ou momento desse processo não podem ser concebidas e desenvolvidas de maneira pontual e/ou isolada. Dessa maneira, a potencialidade percebida pela prática esportiva desenvolvida por usuários do CAPSAD deve estar circunscrita em um planejamento ampliado que integre essas ações com outras que possam dar prosseguimento no processo de reabilitação do sujeito; correndo-se o risco de minimizar o alcance das mesmas caso esse aspecto seja negligenciado.

Evidentemente que desenvolver tal planejamento implica, dentre outras questões, em considerar processos de avaliação para que mais elementos possam ser instituídos de maneira mais eficaz dentro de uma leitura mais abrangente da reabilitação psicossocial. Contudo, ainda que os modelos de avaliação sobre os efeitos da prática esportiva possam ter evoluído nas últimas décadas, durante a experiência relatada no presente estudo não foram aplicados teste algum para verificar a influência dos efeitos da prática esportiva sobre os parâmetros que compõem a saúde dos usuários. Tal limitação se configura em um dado significativo no que se refere em como a prática esportiva em um contexto específico como o da dependência química implica em uma formação específica por parte dos profissionais da saúde, em especial do Educador Físico, já que o uso de drogas ou mesmo de medicamentos podem comprometer o desenvolvimento físico e motor dos usuários fazendo com que a orientação para esse público seja cuidadosamente planejada.

Outro resultado significativo percebido durante esta experiência refere-se ao estreitamento e fortalecimento do vínculo tanto entre os participantes quanto entre os profissionais da saúde e os participantes. Este estreitamento no relacionamento entre os usuários e profissionais da saúde foi compreendido como sendo de relevante importância pois se estenderam para outras atividades entre os mesmos na instituição, como em uma maior participação nas rodas de conversas e na receptividade e aderência ao tratamento medicamentoso por parte dos usuários.

Sabe-se que a construção do vínculo em suas múltiplas interfaces (usuário-profissional; usuário-usuário; usuário família) está estreitamente associado ao desenvolvimento de muitos aspectos na promoção da saúde mental de usuários em tratamento por dependência química. Nesse sentido, percebeu-se que o estreitamente dos vínculos desenvolvidos na prática do futebol poderia ter efeitos não apenas para o desenvolvimento das relações institucionais estabelecidas no CAPSAD durante essa experiência, mas também para outros contextos além da instituição. Contudo, esse não foi um fato constatado pelos profissionais durante essa experiência, o que, mais uma vez, evidencia a necessidade de se ampliar as ferramentas de avaliação dentro das atividades desenvolvidas no CAPSAD.

Por fim, uma última contribuição percebida durante a experiência em questão se refere à questão sobre como as atividades desenvolvidas com o futebol aproximaram entre si os profissionais da instituição, já que, geralmente, todos os profissionais participavam da prática esportiva junto com os usuários. Entende-se que o estreitamento do vínculo entre os próprios profissionais da instituição também é um fator significativo a ser considerado, já que pode refletir direta e/ou indiretamente nas questões relacionadas com a atenção psicossocial e a promoção da saúde mental dos usuários do CAPSAD.

\section{Considerações finais}

A dependência química tem se apresentado como grave problema no campo da promoção da saúde no Brasil. Tal problema não se restringe as consequências que o uso de algumas substâncias pode provocar ao plano biológico. A problemática é complexa e está articulada as esferas psicológica, social e cultural, podendo implicar na acentuação da violência e das desigualdades

Estudos dePsicologia, 22(3), julho a setembro de 2017, 285-292 
sociais e econômicas, uma vez que esta problemática muitas vezes gera efeitos em cadeia, potencializando ainda mais as condições as condições de vulnerabilidade do sujeito frente as possibilidades transformação no contexto onde vive e participa.

O presente estudo, com todas as limitações cabíveis, procurou apresentar o relato de uma experiência profissional que utilizou o esporte como instrumento de fortalecimento psicossocial para usuários que buscaram tratamento para a dependência química. Tal fortalecimento se deu por meio do desenvolvimento dos valores pessoais e sociais inerentes a prática esportiva.

Refletir sobre o desenvolvimento destes valores pessoais e sociais por meio do esporte proporcionou deduzir medidas, ao menos, em duas frentes. A primeira se designa ao caráter profilático frente ao uso de drogas ou da reincidência do uso, potencializando os recursos internos do sujeito e funcionando assim como mecanismo de proteção. Outra frente pode ser apontada pela apropriação de tais valores, como a perseverança, respeito ao próximo e desejo de superação, e assim repercutindo para o direcionamento do tratamento para sujeitos que já fazem uso de drogas e são, portanto, usuários.

Sendo assim, estas são propostas que não se encerram nesta discussão, especialmente pelo fato de que a presente experiência se limitou a um grupo local com poucos participantes. Pelo contrário, pensar na interlocução da prática esportiva e o enfrentamento da problemática do uso de drogas requerem inferências de diversas áreas e segmentos. A ampliação desta relação pode ganhar importantes contribuições mediante o aprofundamento que tal temática necessita e possibilita para o conjunto de ações a respeito da questão do uso de drogas.

Como direcionamento futuro, seria importante que mais pesquisas em outras realidades possam ser desenvolvidas nesta área, especialmente pela escassez de material científico específico na mesma. A produção de material científico especializado poderá contribuir não apenas para o desenvolvimento acadêmico, mas também proporcionar um suporte com mais consistência na formação de profissionais que trabalham, cotidianamente, neste contexto.

\section{Referências}

Carvalho, S. R. (2004a). As contradições da promoção à saúde em relação à produção de sujeitos e a mudança social. Ciência \& Saúde Coletiva, 9(3), 669-678. doi: 10.1590/S1413-81232004000300018
Carvalho, S. R. (2004b). Os múltiplos sentidos da categoria "empowerment" no Projeto de Promoção à Saúde. Cadernos de Saúde Pública, 20(4), 1088-1095. doi: 10.1590/S0102-311X2004000400024

Carvalho, T., Nóbrega, C. L., Lazzoli, J. K, Magni, J. R. T., Rezende, L., Drummond, F. A., ... Teixeira, J. A. C. (1996). Posição oficial da Sociedade Brasileira de Medicina do Esporte: atividade física e saúde. Revista Brasileira de Medicina do Esporte, 2(4), 79-81. Recuperado de http://cev.org.br/arquivo/biblioteca/4035532.pdf

Di Pierro, C., \& Silva, F. S. (2003). Primeiro tempo do terceiro setor Projeto Social. In K. Rubio (Org.), Psicologia do esporte: teoria e prática (pp. 139-154). São Paulo: Casa do Psicólogo,

Duailibi, L. B., Ribeiro, M., \& Laranjeira, R. (2008). Profile of cocaine and crack users in Brazil. Cadernos de Saúde Pública, 24(supl. 4), 545-557. doi: 10.1590/S0102-311X2008001600007

Freire, I. A., Cárdenas, R. N., Manzano, L. A., \& Enriquéz A. R. (2014) As faces do esporte na formação de valores. EFDeportes.com Revista Digital, 19(192). Recuperado de http://www.efdeportes. com/efd192/as-faces-do-esporte-na-formacao-de-valores.htm

Galduróz, J. C. F. (2001). Uso e abuso de drogas psicotrópicas no Brasil. Revista IMESC, (3), 37-42. Recuperado de http://www.imesc. sp.gov.br/pdf/artigo\%202\%20-\%20USO\%20E\%20ABUSO\%20 DE\%20DROGAS\%20PSICOTR\%C3\%93PICAS\%20NO\%20 BRASIL.pdf

Galduróz, J. C. F., \& Caetano, R. (2004). Epidemiologia do uso de álcool no Brasil. Revista Brasileira de Psiquiatria, 26(supl. I), 3-6. doi: 10.1590/S1516-44462004000500002

Kaup, Merighi, \& Tsunechiro, (2001). Avaliação do Consumo de Bebida Alcoólica Durante a Gravidez. Revista Brasileira de Ginecologia e Obstetrícia, 23(9), 575-580.

Kessler, F., \& Pechansky, F. (2008). Uma visão psiquiátrica sobre o fenômeno do crack na atualidade. Revista de Psiquiatria do Rio Grande do Sul. 30(2), 96-98. doi: 10.1590/S0101-81082008000300003

Lane, S. T. M. (2006). O que é Psicologia Social?. Coleção Primeiros Passos (22 ed.). São Paulo: Brasiliense.

Llamas, G. R., \& Suárez, D. C. (2004). Los valores en el deporte. Revista de Educación: Educación y Deporte, Madrid, (335), 9-20. Recuperado de http://www.oei.es/historico/noticias/spip. php?article683

Mailhiot, G. B. (2013). Dinâmica e gênese dos grupos: atualidades das descobertas de Kurt Lewin. Petrópolis: Vozes.

Marques-Teixeira, J. (2001). Drogas e emoções. Saúde Mental: Revista, 3(4), 19-31.

Monteiro, S. S., Vargas, E. P., \& Rebello, S. M. (2003). Educação, prevenção e drogas: resultados e desdobramentos da avaliação de um jogo educativo. Educação \& Sociedade, 24(83), 659-678. doi: $10.1590 / \mathrm{S} 0101-73302003000200018$

Passos, C. B. C. (2011). Internações decorrentes do uso de substâncias psicoativas no Distrito Federal entre os Anos de 2000 e 2009 (Dissertação de Mestrado). Recuperado de http://www.cpqam.fiocruz.br/bibpdf/2011 passos-cbc.pdf

Resolução n. 466, de 12 de dezembro de 2012. (2012, 12 de dezembro). Aprova diretrizes e normas regulamentadoras de pesquisas envolvendo seres humanos. Diário Oficial da União, seção 1.

Ribeiro, M., \& Laranjeira, R. (2010). O tratamento do usuário do Crack. São Paulo: Casa Leitura Médica. 
Dependência química e fortalecimento psicossocial pelas práticas esportivas

Romera, L. A. (2013). Esporte, lazer e prevenção ao uso de drogas: dos discursos equivocados aos caminhos possíveis. Licere, 16(4), 1-19. Recuperado de https://seer.ufmg.br/index.php/licere/article/ view $/ 400$

Sawaia, B. (2013a). Introdução: exclusão ou inclusão perversa? In B. Sawaia (Org.), As artimanhas da exclusão: análise psicossocial e ética da desigualdade social (13ª ed., pp. 7-13). Petrópolis: Vozes.

Sawaia, B. (2013b). O sofrimento ético-político como categoria de análise da dialética exclusão/inclusão. In B. Sawaia (Org.), As Artimanhas da exclusão: análise psicossocial e ética da desigualdade social (13를 ed., pp. 99-119). Petrópolis: Vozes.
Siqueira, D. F., Moreschi, C., Backes, D. S., Lunardi, V. L. Lunardi Filho, W. D., \& Dalcin, C. B. (2012). Repercussões do uso de crack no cotidiano familiar. Cogitare Enfermagem, 17(2), 248-254. doi: 10.5380/ ce.v17i2.23518

Soares, C. B., \& Jacobi, P. R. (2000). Adolescentes, drogas e AIDS: avaliação de um programa de prevenção escolar. Cadernos de Pesquisa, (109), 213-237. doi: 10.1590/ S0100-15742000000100010

United Nations Office on Drugs and Crime. (2015). World Drug Report 2015. Recuperado de http://www.unodc.org/documents/wdr2015/ World_Drug_Report_2015.pdf

1. Centro de Atenção Psicossocial que oferece serviços especializados para tratamento de usuários com dependência química de álcool e outras drogas.

2. O termo empoderamento e seus derivados não existem na gramática da língua portuguesa. Contudo, a utilização deste termo está apoiada em sua denominação original na língua inglesa empowerment, como será explicado posteriormente.

Marcelo Simões Mendes, Doutor em Saúde Coletiva pela Universidade Estadual de Campinas (UNICAMP), é Professor do curso de Psicologia da Universidade Paulista de Campinas (UNIP). Endereço para correspondência: Av. Comendador Enzo Ferrari, 280 - Swift - Campinas, SP. CEP: 13045-770

Telefone para contato: (19) 3776-4000. Fax: (19) 3776-4016. E-mail:m_smendes@yahoo.com.br

Recebido em 05.Fev.16 Revisado em 23.Mai.17 Aceito em 08.Ago.17 